\title{
The Double Guru: Layers of Witnessing
}

\author{
Amanda Levey with Rachel Grimwood \\ Australian, New Zealand and Asian Creative Arts Therapies \\ Association, New Zealand
}

\begin{abstract}
This creative contribution describes a duoethnography research practice that Amanda and Rachel have developed - a process of witnessing both each other's solo as well as shared movement-based creative explorations in nature. This creative partnership has been developed over a period of over ten years and the pair often teach and perform together. They jokingly refer to their witnessing process as 'the double guru' as they feel that their joint creative work yields a form of wisdom not available to them as individuals. It is also a comment on the fact that their pedagogy relies on an inter-relational style that is incompatible with a didactic individualistic model. Images and a transcript of verbal reflections from video and greenscreen technology are presented here to give examples of their creative process.
\end{abstract}

Keywords: witnessing, video, greenscreen, movement, duoethnography

My creative process is rooted in the movement-based Halprin Life/Art process. I trained at Tamalpa Institute in the early 80s, returning for intensive work in nature over a period of 10 years in the 1990s and early 2000s. After my initial training, I felt very isolated and so I began to experiment with the medium of video so that - in the absence of others to witness my movement expressions - I could let the camera be the witness. I could then view my own expressions and learned to edit the footage to make video pieces that incorporated not only multiple sessions of movement shot in different locations (mostly in nature) but also music. I could also experiment with camera and editing effects. I could view the videos over time and also show them to others - creating a whole new creative outlet for myself. I was also able to share my creative process with others and receive feedback and understanding.

Gradually I have built up my own community in this part of the world and have kept experimenting with the use of movement in nature and video. I have enjoyed many years of creative partnership with a colleague and dear friend Rachel Grimwood. We regularly meet to move, draw, reflect, write and witness each other. We will sometimes witness individual work and sometime collaborate creatively - combining our images and writing for movement inspiration.

A luxury and highlight of our work together are the times we retreat to former park rangers' cottages in our gorgeous regional parks. We spend our days seeking resources and metaphors in our natural environment. Elements of nature - wind, water, rock, skybecome part of our creative process and, in turn, become part of our meaning-making. We witness and video each other's movement explorations and sometimes we collaborate 


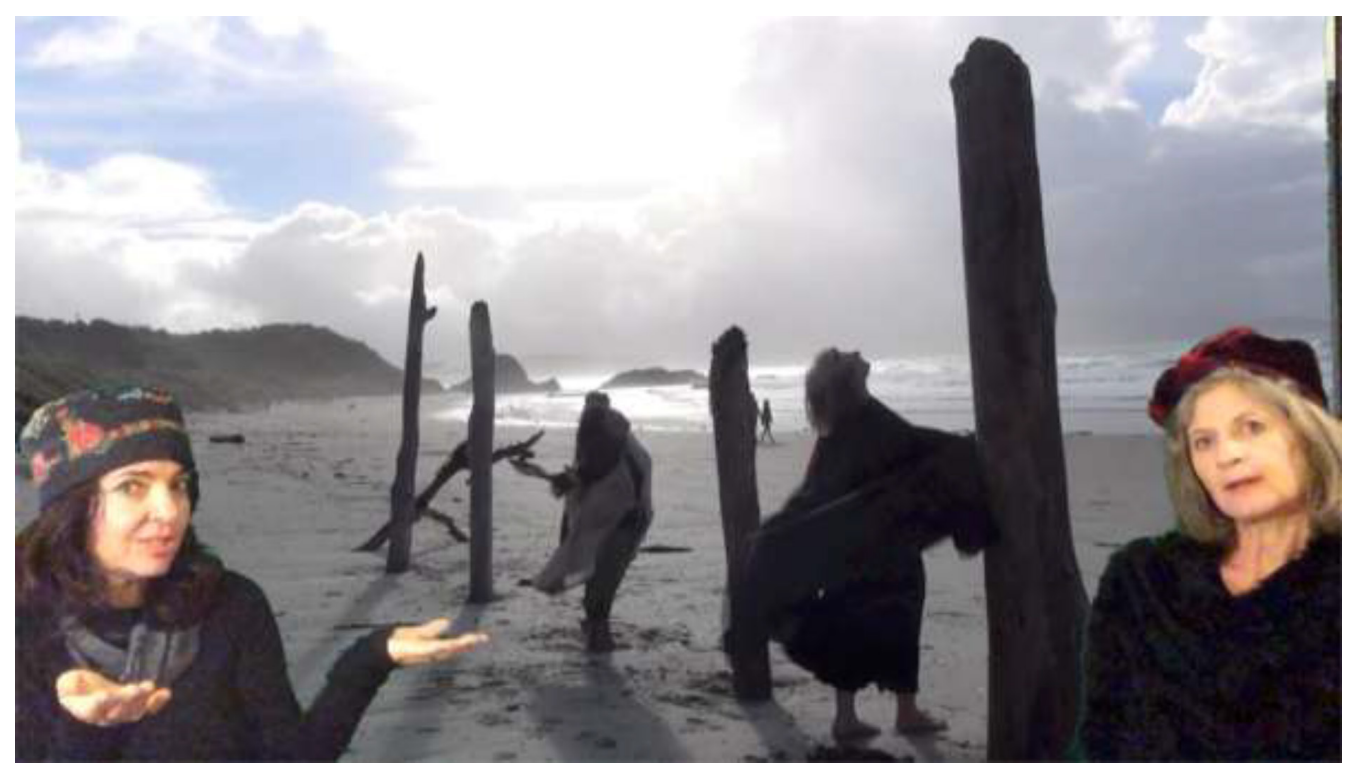

FIGURE 1

together and use the camera on a tripod to capture our joint creative work. In the evenings, we watch the completed footage projected onto the wall while we discuss what we saw, felt, imagined and understood - and we also plan for the next day's adventure.

Recently, we have been experimenting with another layer of witnessing in our video process:greenscreen. This has allowed us to not only use the camera as a witness so that we can reflect and witness our work, buthas also allowed us to add another layer of documentation and creativity to this reflective process. Some examples can be found here with, finally, an image of a greenscreen movement exploration of a jointly constructed poem.

Dialogue for Figure 1:

R: Having these props that we didn't put there, having these stable structures allowed a different sort of experimentation and improvisation to happen...

A: Because before that we had been improvising with water which was constantly moving and coming in and out. And light that was changing constantly -

$\mathrm{R}$ : It was a relief to get to something that was stable and still.

Dialogue for Figure 2:

R: I guess we are actually playing with echoing the actual shape of the wood...

A: Yes, because it looks like it's got elbows and it's got legs -

$\mathrm{R}$ : Yes, it really projects itself and it brings about a sense of extension into the space... 


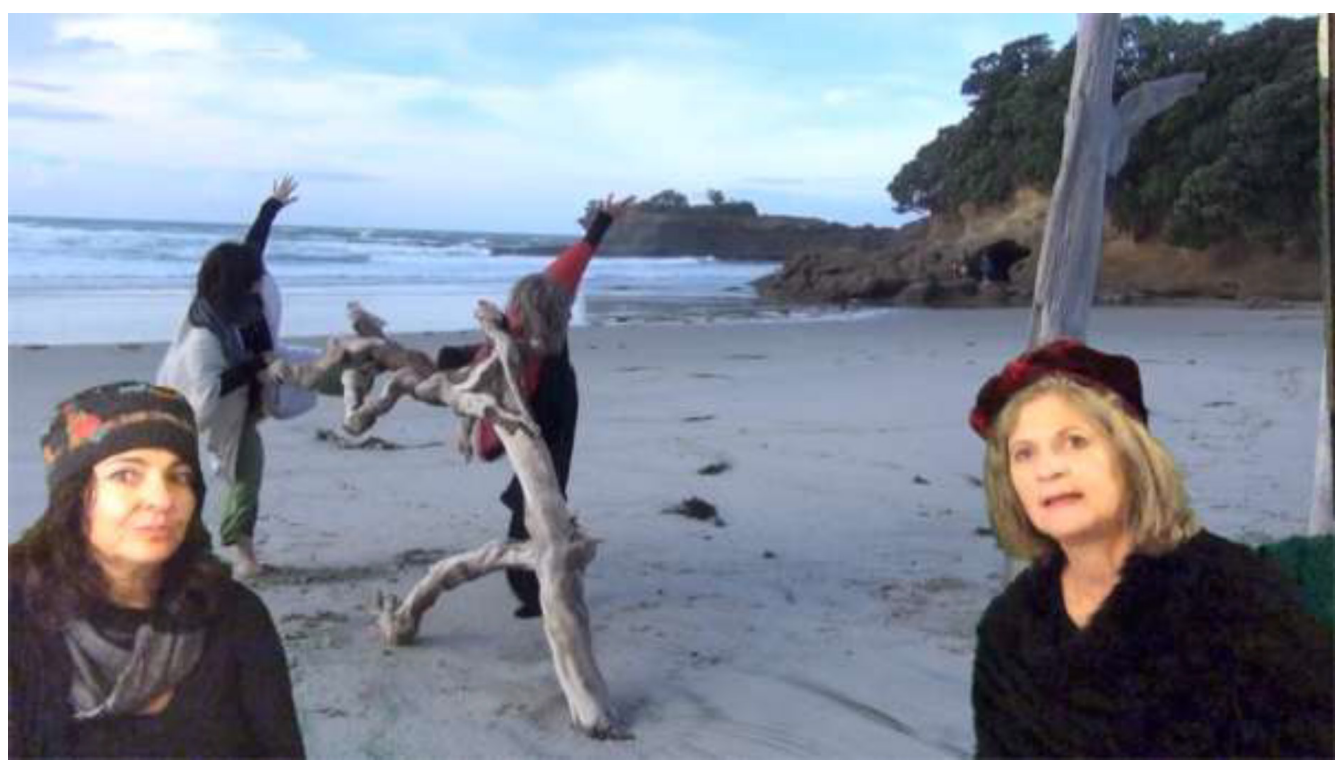

FIGURE 2

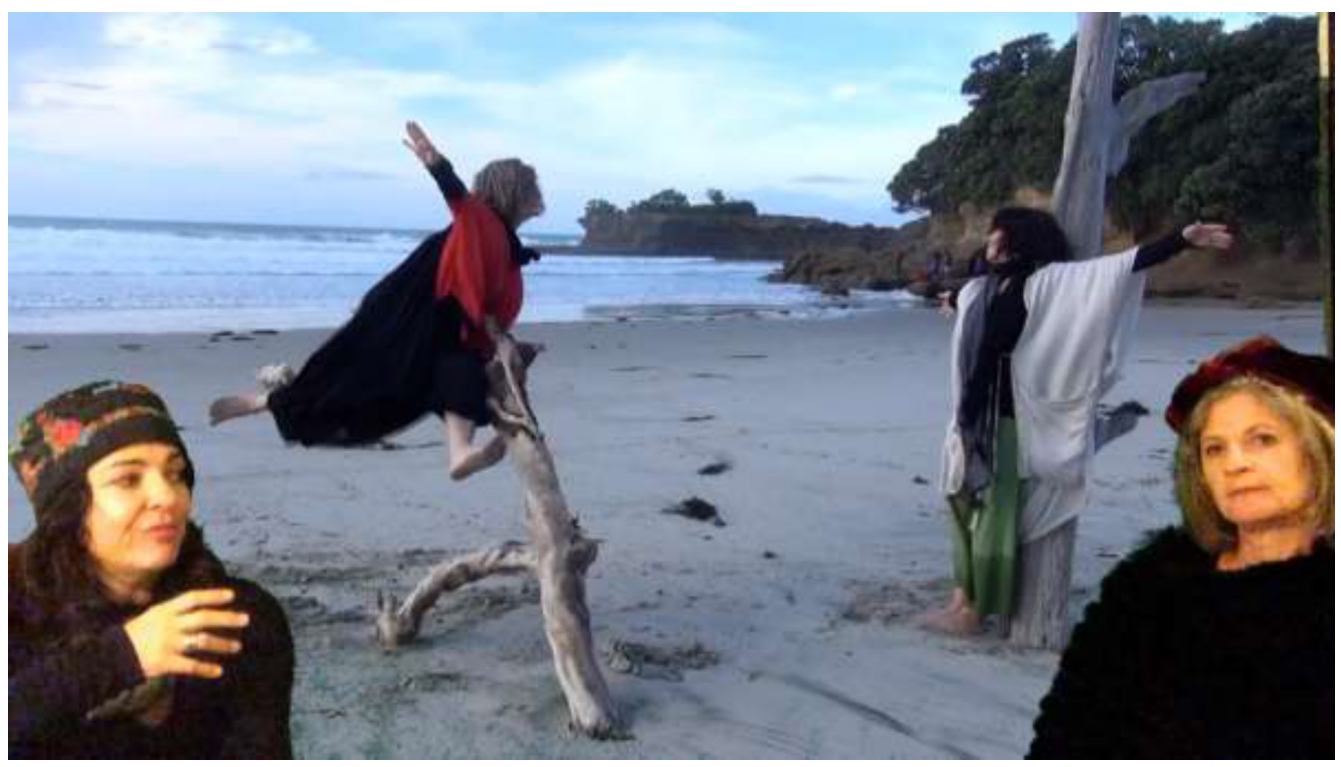

FIGURE 3

Dialogue for Figure 3:

R: You are looking at balance in a really different way; there's been a past metaphor where you were standing your ground but pulled by separate elements - but here you are more by relating to and finding balance... 
A: Yes, and one of the things that I wrote about later in our poems was the "I at the centre.' There is something about feeling really centred within the extension....and only being able to extend and balance because I am experiencing my centre as being so strong.

R: Yes, so your own sense of core and your own sense of identity at the centre give you the strength to extend and balance rather than having to hold onto and being pulled in different directions.

A: Yeah, and I was really enjoying that elevation there and extending all the way out through my feet and extending all the way out through my arms and really be able to feel the sense of new possibilities...

Dialogue for Figure 4:

A: I have been meaning to ask you what it was like to work inside the cave again because it was a very significant place for you...

R: I think it was a couple of weeks before my father died...he was really ill, and I didn't even know if we would get to come to Tawharanui that time, and I did that piece of coming into the light through the cave. I was really aware of it when we first came to the beach this time and when we came to the cave...but it wasn't consciously in my mind once I was there...I knew that I had moved in it before and I really had it in my mind at first. But it was a totally new piece.

A: Yeah it felt like that to me when I was filming it, partly because the water was coming in and it probably wasn't possible to be 'in two places at once' internally for you -

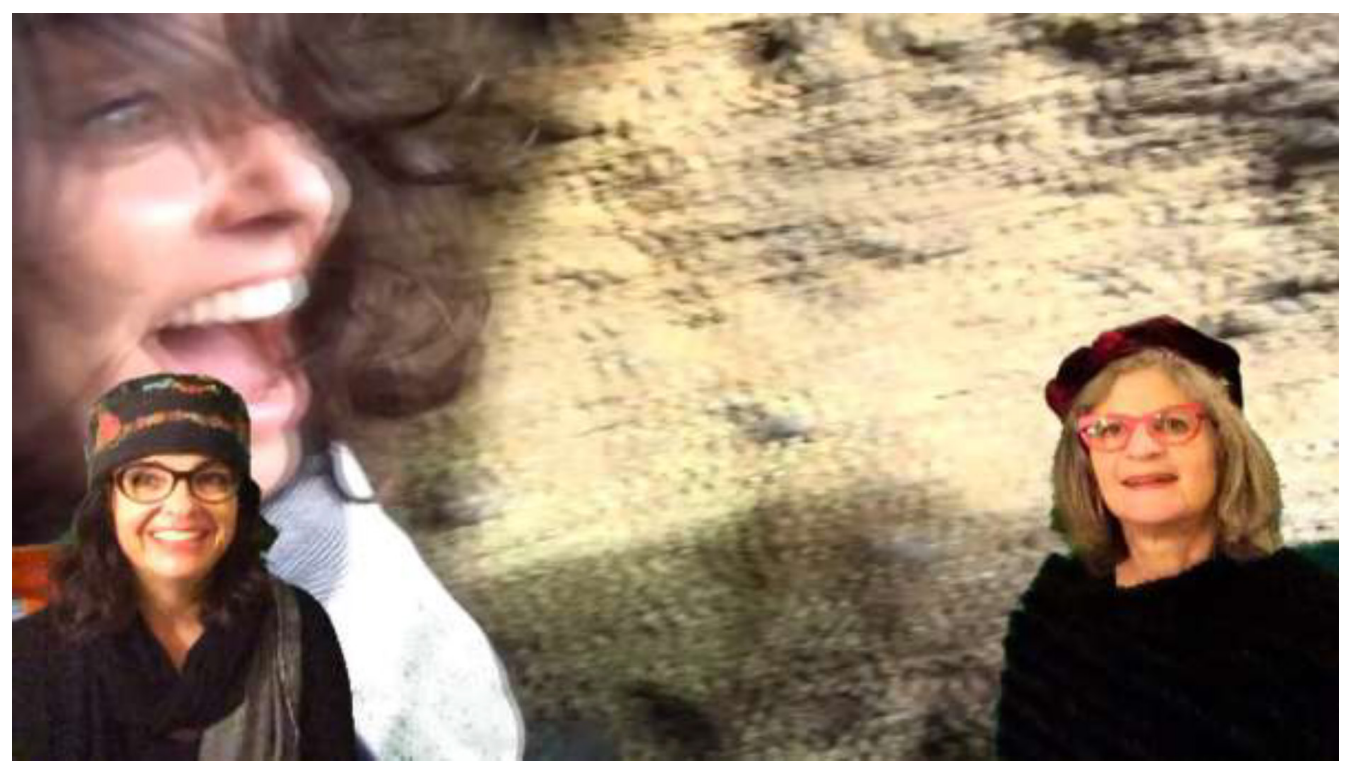

FIGURE 4 
R: Exactly! Yes, it kept me really vital. I had to be really here and now; I couldn't be off in my mind. The ocean was coming in and there was lots of wind!

Dialogue for Figure 5:

$\mathrm{R}$ : There has been, for me, an integration and a new experience of being with mortality and my own internal sense of a connection between being alive and being dead. I would say the passing of my father and then my mother has developed a sense of relationship with someone deceased. I have a sense of ongoing relationship with them.

A: What's interesting to me is that you came completely out of the cave; that was partly to do with the water being a problem, but it is almost like you found a new -

R: I stepped out of it and found higher ground.

A: Yes, you found this height - this perspective - and afterwards you did talk about how you enjoyed being 'up.' On that day...everywhere else the sky was grey and yet there it was this really vivid blue and there was something about you being framed against that really clear sky that, to me, felt really significant.

Dialogue for Figure 6:

A: And you moved around on the rock with such ease... whereas before, in times gone by, you would have chosen really jagged rocks and would have had real difficulty moving on them; do you remember?

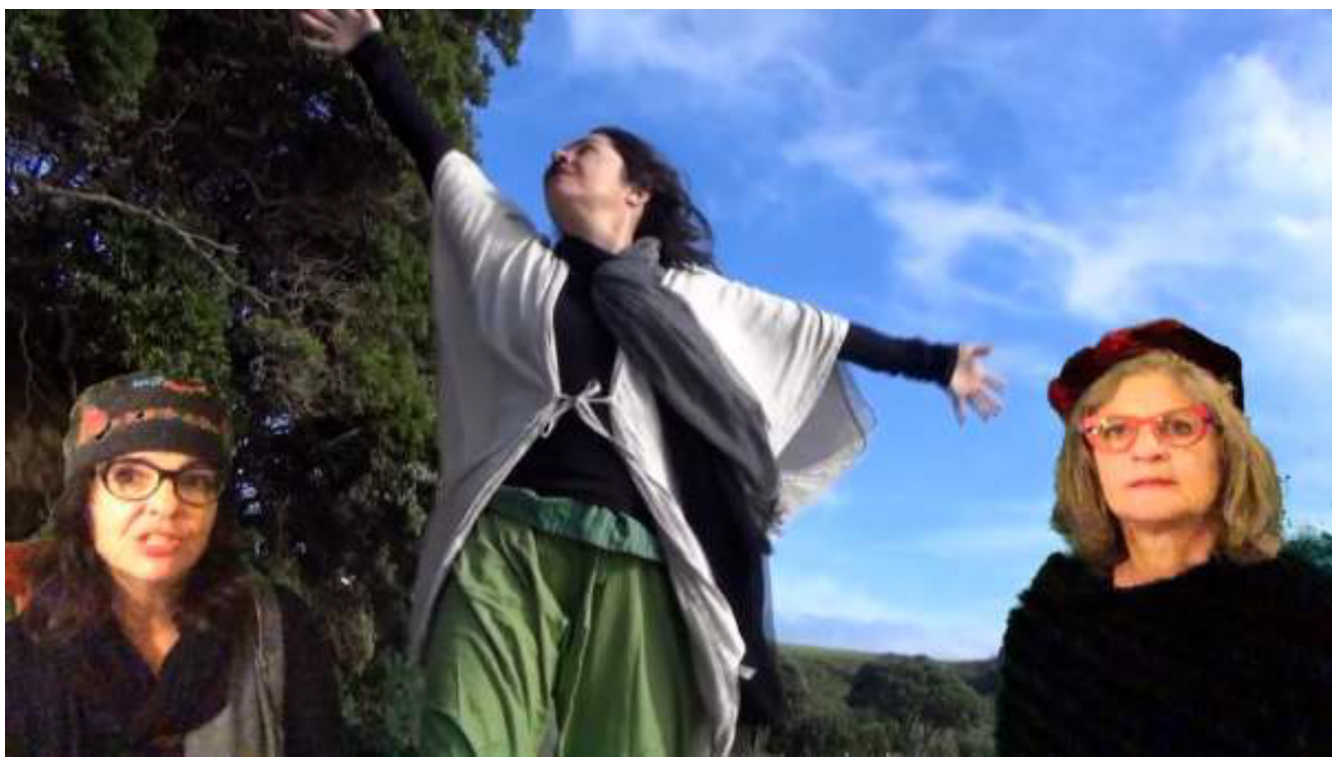

FIGURE 5 


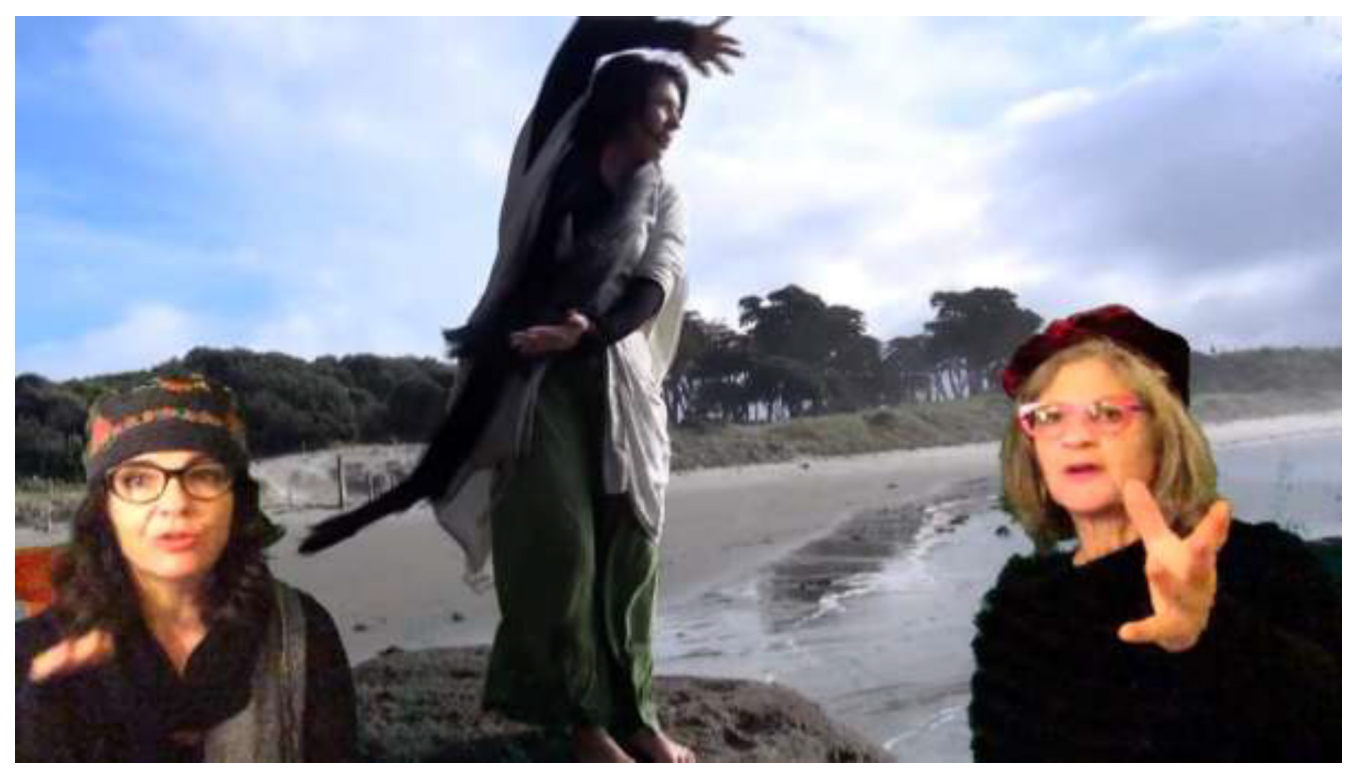

FIGURE 6

R: Yes always, and just the opposite here!

A: "Why am I choosing these really difficult terrains?" you would ask.

R: And look - I rose myself to high ground out of water and smooth rock!

A: Yeah, that you could move along very easily against a clear sky -

R: Yes, I've had enough of writhing around on corally sharp things -

A: Hurting yourself...doing too much! I think you just got off and left the scene... and then you went out to be with the wind and the ocean.

R: That's right, I did...

Dialogue for Figure 7:

$\mathrm{R}$ : This is nice because we have done something together and we have more spaciousness.

A: We've got this enormous vista behind us and we can just play with it...I seem to remember this part as an ease of moving together; we've let go of all the frenetic movement and we've come back to being much more simple. And there's that beautiful scene with that beautiful light.

$\mathrm{R}$ : And I almost get the sense of looking out to sea the same sense as being there; I like the resonances and the ripple effect I get sitting here and watching it on the screen and feeling it in my body.

A: Remembering being there and the feeling of our feet on the sand and wind in our clothes and in our hair. 


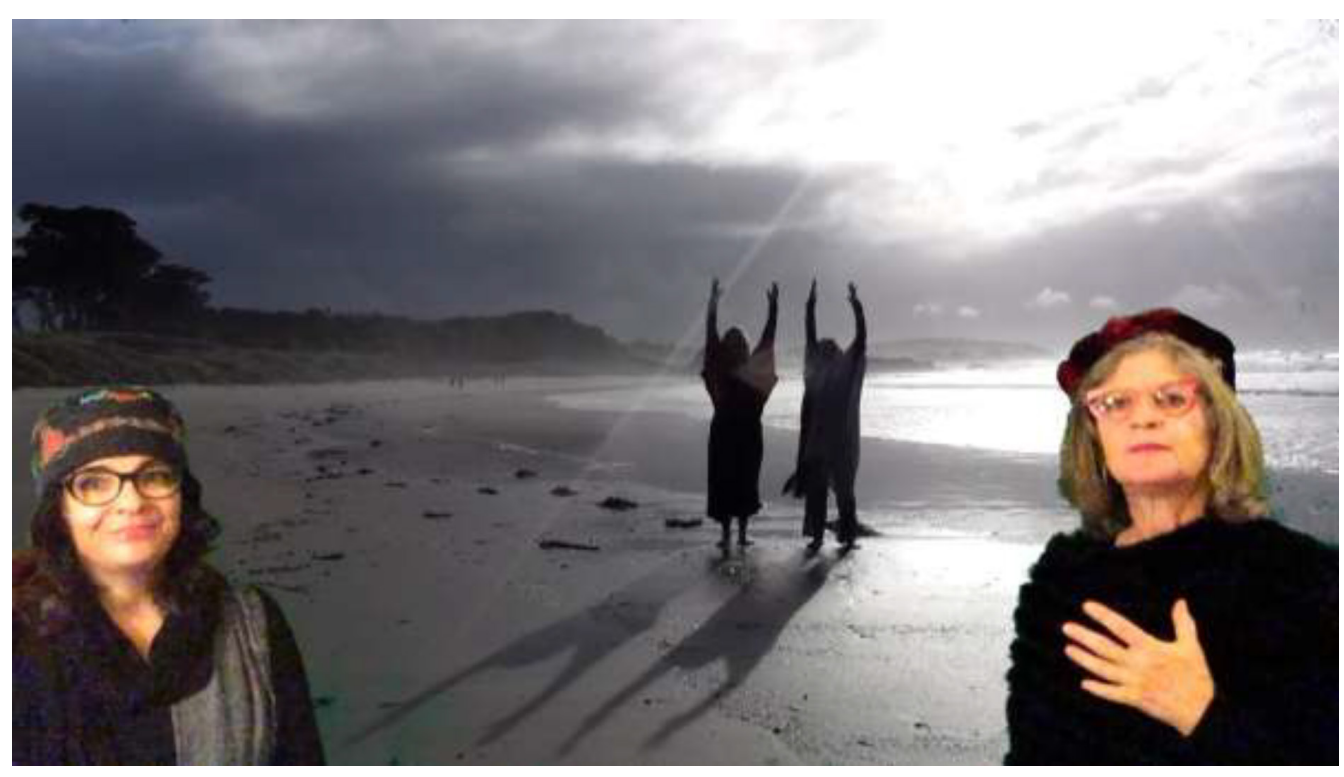

FIGURE 7

Dialogue for Figure 8:

Improvising to a joint poem:

In my dream

Circling with growing power

In my dream colour shining through in glimpses

And now the ocean is shaft of light

First wait ...inevitably the wait

Light and shadow, wild illuminations

Eye/I at the centre all seeing

In my dream, circling with growing power

In my dream colour shining though in glimpses

And now the ocean is shaft of light

First wait ...inevitably the wait

Light and shadow, wild illuminations

In my dream, colour shining through

In my dream

Circling with growing power

Eye/I at the centre

ocean is shaft of light 


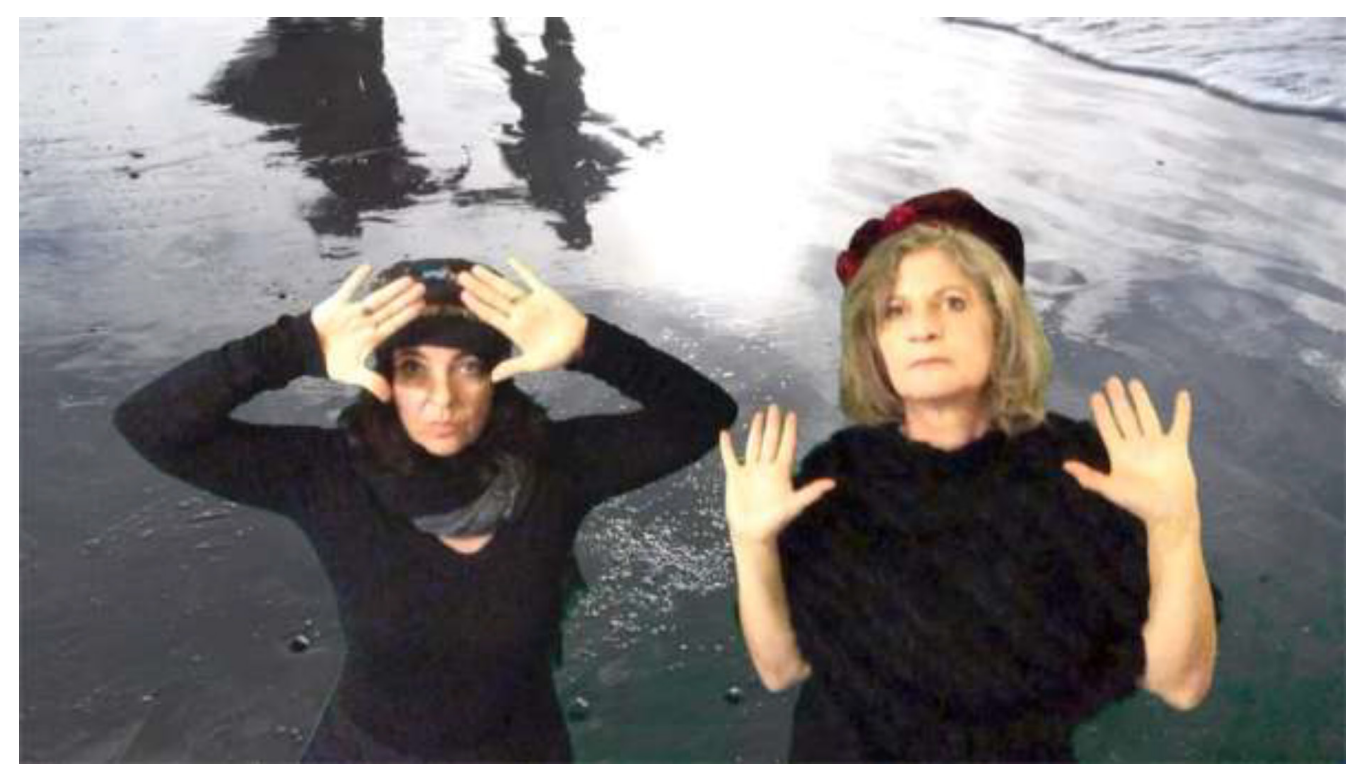

FIGURE 8

inevitably the wait

inevitably the wild illumination

Light and shadow glimpsing through

Colour in my dream

And now...wait... inevitably the wait

Dream - Eye/I at the centre

colour shining through

all seeing, glimpses

Light, shadow

Illuminations

wait... inevitably...light

growing power circling

Dream...glimpse...shining through

At the centre - wild centre

All seeing centre

\section{About the Authors}

Amanda Levey, (MA AT, BA(Hons)Psych, Registered Psychologist, AThR). Amanda studied Psychology at the University of Melbourne and subsequently trained extensively in the Halprin Method in the USA. This model is an integration of movement/dance, visual arts, performance techniques and therapeutic practices. She gained her MA in Arts 
Therapy at Whitecliffe College of Arts and Design in Auckland, New Zealand, and is the current Programme Director of that programme. Amanda is on the Board of ANZACATA (Australian, New Zealand and Asian Creative Arts Therapies Association). She has presented at conferences in Australia, New Zealand, Asia and Europe.

Rachel Grimwood (D.Clin Psych.) runs a private practice in Auckland where she utilizes a range of talking, sand tray, movement and creative therapies. Her doctoral thesis used grounded theory to explore the links between post-natal distress and sexual trauma with a focus on embodied distress. She values the power of therapeutic movement to support the personal processing of that material. When she returned to New Zealand about 14 years ago, she began to teach mindful movement workshops in the community and further developed her love for dancing on beaches. As this is also one of Amanda's favourite things to do, Rachel and Amanda developed a creative partnership; over the years they have supported each other to make space to play, explore and create performance art. Rachel has also taught with Amanda in the arts therapy masters programme at Whitecliffe College. 